\title{
Posterior capsulotomy and retinal detachment following extracapsular lens surgery
}

\author{
H. C. SEWARD AND R. M. L. DORAN \\ From the Western Ophthalmic Hospital, Marylebone, London
}

SUMmARY A retrospective analysis of the results of extracapsular cataract surgery with and without implant is presented. Surgery was performed by a group of consultants and registrars from 1975 to 1982 , and minimum patient follow-up was 12 months (mean $26 \cdot 2$ months). The incidence of postoperative capsulotomy was $14 \cdot 3 \%$, but the need for this procedure declines, becoming negligible after 3.5 years. Of 242 eligible eyes, aphakic retinal detachment occurred in only one.

Extracapsular lens extraction has in the last decade returned to popularity as a technique in cataract surgery, not only as regards its merits in comparison to those of the pure intracapsular method but particularly when combined with pseudophakos implantation. ${ }^{2}$ In 1961 Heath, ${ }^{3}$ having had 20 years' experience of both techniques, including 2 years with chymotrypsin, felt that an intact posterior capsule offered considerable advantages in preventing complications, notably that of aphakic retinal detachment, and this opinion is supported by Percival et al. ${ }^{4}$ However, a number of cases require subsequent posterior capsulotomy to restore a clear optical axis. Figures quoted for the incidence of secondary surgery vary from $9 \%{ }^{5}$ to $51 \%$ " according to study criteria.

We present the results of a retrospective study of extracapsular surgery, with and without implant, performed by a group of surgeons at the Western Ophthalmic Hospital between 1975 and 1982. We have looked in particular at the incidence and timing of capsulotomy and the occurrence of aphakic retinal detachment (ARD).

\section{Materials and methods}

The hospital records of a consecutive series of 267 patients who underwent elective extracapsular lens extraction at this hospital were analysed. Surgery was performed by a group of 4 consultants and 4 registrars employing a generally similar extracapsular technique as described by Marsh and Andrew. ${ }^{7}$

Information was recorded on all those patients with 12 months' follow-up or longer. This included Correspondence to Miss H. C. Seward, FRCS, Western Ophthalmic Hospital, Marylebone Road, London NW1. age, sex, best postoperative visual acuity and its time of achievement, incidence of capsulotomy and ARD, and causes of postoperative visual acuity below 6/12. Where sufficient information was lacking we contacted the general practitioner or the patient concerned to establish postoperative visual status. In some cases clinical review was required. We recorded data on 244 eyes belonging to 227 patients (137 female, 90 male). The remaining 40 patients were excluded because 10 had died, 10 had moved abroad, and 20 could not be traced.

\section{Results}

One hundred and fifty three cases in our series received an intraocular lens implant (IOL group) and 91 were plain extracapsular extractions (EC group). The period of follow-up is shown in Table 1. There were no secondary implants. Information was not available for cases in which elective implant surgery was aborted. Lens implant type is shown in Table 2.

Table 1 Type of surgery and follow-up

\begin{tabular}{ll}
\hline Total eyes & 244 \\
Plain extracapsular (EC) & 91 \\
With implant (IOL) & 153 \\
Minimum follow-up & 12 months \\
Mean follow-up & $26 \cdot 2$ (range 12-93) months \\
\hline
\end{tabular}

Table 2 Implant type

$\begin{array}{lr}\text { Binkhorst 2-loop } & 97 \\ \text { Boberg-Ans } & 54 \\ \text { Federov } & 1 \\ \text { Shearing } & 1\end{array}$




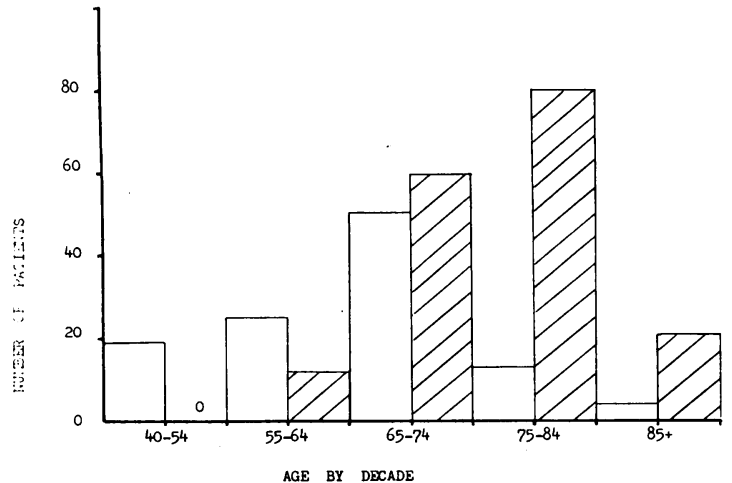

Fig. 1 Age distribution of patients. $\square=E C . \quad=I O L$.

The Binkhorst 2-loop style implant was used almost exclusively until 1980 .

Age of patients. The range of age at surgery was 40-95 years and the distribution is shown in Fig. 1.

Postoperative visual acuity. Table 3 shows the visual acuity results for the whole group of 244 eyes. It was found that about $7 \%$ of cases were delayed in achieving their best acuity. This was probably due to transient cystoid macular oedema or change in final refraction. We found 21 cases in which poor results could be attributed to pre-existing pathology, such as glaucoma and macular degeneration. In Table 4 these cases have been excluded in the presentation of the visual results.

Surgical pathology. The complications due to surgical pathology are shown in Table 5. The 3 cases of capsular opacity cited did not undergo capsulotomy during the period of study, and they had a best visual acuity recorded in the 6/18 to 6/60 range. We found 3 cases of corneal oedema (all IOL group) occurring in the shorter postoperative period. Two were discovered immediately after surgery, and one became decompensated at 4 months. The duration of followup is not long enough in this study to reveal all the cases which may eventually be complicated by corneal oedema. We found only one case in which poor vision was definitely attributable to persistent cystoid macular oedema (IOL group); the visual acuity in this case was less than 6/60. A single case of early postoperative endophthalmitis was treated with local and systemic antibiotics and steroids. No organism was identified, and after resolution of the inflammation there was a dense membrane behind the pseudophakos. This was successfully divided with the ocutome at 5 months after surgery and vision recovered to $6 / 36$.

Capsulotomy. Elective posterior capsulotomy was performed during primary surgery in six cases $(5 \mathrm{EC}$, 1 IOL). Thirty-four eyes required posterior capsulotomy subsequently (Table 6). We counted the
Table 3 Postoperative visual acuity (244 eyes)

\begin{tabular}{lcc}
\hline & \multicolumn{1}{l}{$I O L$} & \multicolumn{1}{l}{$E C$} \\
\hline Not less than $6 / 12(0-3$ months) & $127(83 \%)$ & $69(75 \cdot 8 \%)$ \\
Not less than 6/12 (3-9 months) & $13(8 \cdot 5 \%)$ & $6(6 \cdot 6 \%)$ \\
$6 / 60-6 / 18$ & $7(4 \cdot 6 \%)$ & $11(11 \%)$ \\
Less than $6 / 60$ & $6(3.9 \%)$ & $5(5 \cdot 5 \%)$ \\
\hline
\end{tabular}

Table 4 Postoperative visual acuity excluding pre-existing pathology and those requiring capsulotomy

\begin{tabular}{lcc}
\hline & $I O L$ & $E C$ \\
\hline Not less than $6 / 12$ & $140(95 \cdot 8 \%)$ & $75(97 \%)$ \\
$6 / 60-6 / 18$ & $2(1 \cdot 4 \%)$ & $2(3 \%)$ \\
Less than $6 / 60$ & $4(2 \cdot 8 \%)$ & \\
\hline
\end{tabular}

Table 5 Surgical pathology causing reduced visual acuity

\begin{tabular}{ll}
\hline Capsular thickening & 3 \\
Corneal oedema & 3 \\
Persistent cystoid macular oedema & 1 \\
Endophthalmitis & 1 \\
\hline
\end{tabular}

Table 6 Incidence of postoperative capsulotomy $(n=244)$

\begin{tabular}{lll}
\hline & No. & $\%$ \\
\hline EC & 10 & $11 \cdot 5$ \\
IOL & 24 & $15 \cdot 7$ \\
Total & 34 & $14 \cdot 3$ \\
\hline
\end{tabular}

number of capsulotomies in each 4-month period, and with reference to the number of eyes eligible for the procedure at the start of each period we calculated the percentage risk per year of the need for posterior capsulotomy. Regression analysis shows the decline in risk to be linear (Fig. 2). The visual results following posterior capsulotomy are given in Table 7. Two of the five eyes which did not improve are already listed in Table 5; three had pre-existing pathology.

Fellow eyes. Seventeen patients contributed both eyes to the study-10 in the EC group and 7 in the IOL group. Two patients required bilateral posterior capsulotomy, and corneal oedema developed in one eye of a third patient. We do not consider that this proportion of patients contributing both eyes to the series has significantly biased the results.

Retinal detachment. Of the 244 eyes in our study 2 (both EC) showed evidence of pre-existing retinal detachment. One had a diabetic traction detachment and the other an unsuspected rhegmatogenous detachment. These were excluded from our analysis of aphakic retinal detachment.

We found only one case of aphakic retinal detachment, which occurred 30 months after surgery and 26 months after posterior capsulotomy in a patient with a Binkhorst 2-loop implant. This was successfully 


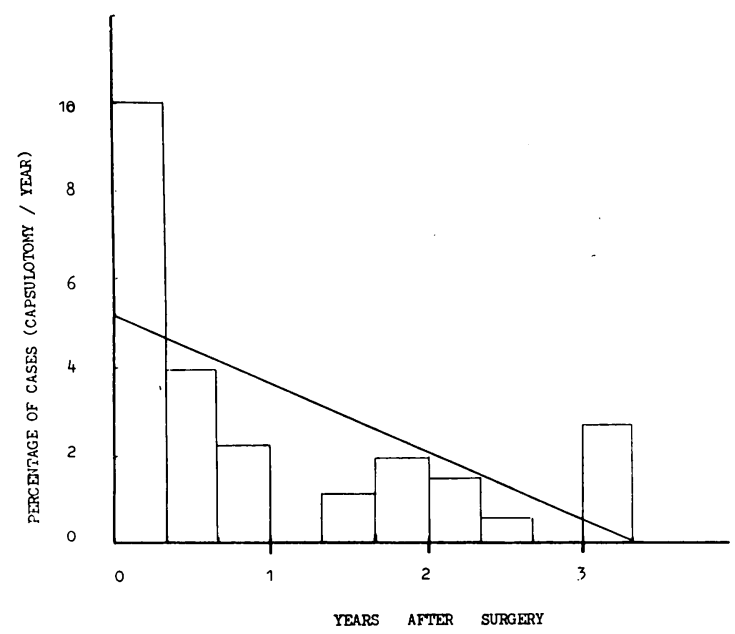

Fig. 2 Percentage of cases undergoing secondary posterior capsulotomy per year, calculated for each 4-month period following primary surgery up to 4 years. A linear fit to the data is highly significant: $r=0.646 ; 0.02<p<0.05$; variance ratio 369.6 in excess of the $0.1 \%$ critical point linear fit.

Percentage cases per year $=5 \cdot 30-1.52 \times$ (time after surgery in years).

treated with a buckling procedure to a single round peripheral hole and vision restored to 6/24. A symptomatic flat $U$ tear in the retina of a patient in the EC group occurred 7 months after surgery and was treated successfully with cryopexy.

\section{Discussion}

Our visual acuity results (Table 3 ) compare favourably with those of Jaffe, ${ }^{2}$ who found vision of $6 / 12$ or better in $89.5 \%$ of 200 cases of extracapsular extraction with implant, and those of Karp and Scheie, ${ }^{8}$ who found visual acuity of $6 / 12$ or better in $84.7 \%$ of 904 cases of plain extracapsular cataract extraction.

The incidence of aphakic retinal detachment in our series is very low when we consider that our group contains all refractive types. Percival et al. ${ }^{4}$ found an incidence in extracapsular surgery of $0 \cdot 2 \%$ when cases of vitreous loss were excluded, with mean follow-up of 2.4 years. Scheie et al. ${ }^{9}$ reported $2.2 \%$ incidence of ARD in 5541 eyes, 5417 of which underwent intracapsular extraction with minimum follow-up of 6 months. Since most detachments occur in the first 2

Table 7 Results following capsulotomy $(n=34)$

\begin{tabular}{lcr}
\hline & No. & $\%$ \\
\hline Not less than $6 / 12$ & 28 eyes & $82 \cdot 4$ \\
$6 / 18-6 / 60$ & 4 eyes & $11 \cdot 7$ \\
Less than $6 / 60$ & 2 eyes & 5.9 \\
\hline
\end{tabular}

years after surgery, ${ }^{10}$ our period of review is adequate. Our single case of ARD occurred in a patient who had undergone posterior capsulotomy. It is possible that this detachment may be related to the degree of manipulation required to divide the capsule.

If we include the 3 cases of unoperated capsular opacity, the overall incidence of the need for postoperative capsulotomy is $15.1 \%$ in our series. We disagree with the findings of Wilhelmus and Emery ${ }^{6}$ that the incidence of capsular opacity is increased in those patients with longer follow-up, reaching $51 \%$ in those followed for more than 4 years. We have clearly demonstrated that among our patients the risk of need for capsulotomy in fact declined in a linear fashion and became negligible after 3.5 years (Fig. 2). We feel that this is an acceptable frequency of need for a relatively minor surgical procedure which can be performed without hospital admission under local anaesthetic. In many cases the opaque membrane may be divided without admitting vitreous into the anterior segment, and so the ocular geometry is preserved. With the advent of the YAG-laser it is hoped this procedure will become still less problematic. Posterior capsular opacification is best prevented by good operative technique, especially in regard to complete removal of anterior capsule and lenticular cortex. ${ }^{11}$ As surgeons gain experience in the extracapsular technique, we believe the incidence of capsulotomy should fall. The advantages of an intact posterior capsule in maintaining stability of the anterior vitreous and of the pseudophakic lens, and the lower incidence of cystoid macular oedema $\mathrm{a}^{12}$ and aphakic retinal detachment, seem fully to outweigh the disadvantages of capsulotomy.

We thank the consulting surgeons at Western Ophthalmic Hospital for permission to study their patients and in particular Mr R. J. Marsh and Mr R. J. H. Smith. Professor R. F. Fisher provided us with invaluable help with our statistical analysis. Mrs S. Tant very kindly prepared the manuscript.

\section{References}

1 Binkhorst CD. 500 Planned extracapsular extractions with iridocapsular and iris clip lens. Ophthalmic Surg 1977; 8: 37-44.

2 Jaffe NS. Changing scene of intraocular implant surgery. Am J Ophthalmol 1979; 88: 819-28.

3 Heath WE. Changing trends in cataract surgery. A survey of results over 20 years. Trans Ophthalmol Soc UK 1961; 81: 697704.

4 Percival SPB, Anad V, Das SK. Prevalence of aphakic retinal detachment. Br J Ophthalmol 1983; 67: 43-5.

5 Pearce JL. Modern simple extracapsular surgery. Trans Ophthalmol Soc UK 1979; 99: 170-6.

6 Wilhelmus KR, Emery JM. Posterior capsule opacification following phacoemulsification. Ophthalmic Surg 1980; 11: 264 -7 .

7 Marsh RJ, Andrew NC. Experience with extracapsular extraction and Binkhorst 2-loop intraocular lenses. Preliminary communication. J R Soc Med 1981; 74: 892-5. 
8 Karp LA, Scheie HG. Results of 1000 consecutive intracapsular cataract extractions. Ann Ophthalmol 1981; 13: 1201-3.

9 Scheie HG, Morse PM, Aminlari A. Incidence of retinal detachment following cataract extraction. Arch Ophthalmol 1973; 89: 293-5.

10 Ashrafzadch MT, Schepens CL, Elzencing II, Moura R, Morse
P, Kraushar MF. Aphakic and phakic retinal detachment. Arch Ophthalmol 1973; 89: 476-83.

11 Smith RJH, Doran RML, Casswell AG. Extracapsular cataract extraction: some problems. $\mathrm{Br} J$ Ophthalmol 1982; 66: 183-5.

12 Miami Study Group. Cystoid macular edema in aphakic and pseudophakic eyes. Am J Ophthalmol 1978; 88: 45-8. 